\title{
Water vapor induced airborne rotational features
}

\author{
Roman Marks \\ University of Szczecin, Faculty of Geosciences, Physical Oceanography Unit, Mickiewicza 16, 70-383 Szczecin, \\ Poland,e-mail: roman.marks@usz.edu.pl
}

\begin{abstract}
In order to study the rotational features induced by evaporating water several laboratory experiments were conducted with airborne rotary detection discs made of absorbent cotton wool and ultralight polyurethane foam discs. Measurements indicated that water vapor develops and transits into the air an upwardly directed counterclockwise rotary motion in the Northern Hemisphere, and a clockwise motion in the Southern Hemisphere. Additionally, measurements of the thermal structure of the air/water interface indicated that evaporating water may gather rotational momentum in the warmer subsurface layer. The conducted observations suggest that the process of water evaporation may be based on the grouping of some coherently spiraling molecules in the liquid phase. The interacting molecules combine their partial rotational momentums, thus allowing the top molecule to transit via the surface tension microlayer and become airborne. At the moment of evaporation, the gathered rotational energy is taken over by the free bi-hydrogen rotor-arm of the evaporating molecule that starts to revolve. Next, the water vapor-induced rotational share of the kinetic energy is likely to be redistributed among other gaseous molecules and transferred into heat (during condensation) that further energizes the airborne convective loops. In order to confirm the rotary effects induced by water vapor, several field experiments were conducted with airborne rotary detection ribbons in the Northern Hemisphere. The observations confirmed that a more enhanced counterclockwise spiraling motion of air is found with air currents under atmospheric lows of a higher relative humidity, while weaker and clockwise directed rotary dominates under atmospheric highs.
\end{abstract}

Keywords: rotational configuration of water molecule, airborne eddies, rotational features of greenhouse gasses

Submitted 24 May 2018, revised 6 December 2018, accepted 22 February 2019

\section{Introduction}

Considering that approximately $80 \%$ of solar energy is intercepted by the oceanic water up to $100 \mathrm{~m}$ depth, and that approximately $90 \%$ of the Earth's surface in the tropics is covered by oceans, the tropical oceanic belt accumulates most of the solar energy intercepted by the Earth. The accumulated energy is then redistributed by surface oceanic currents that transport heat mainly along the east coasts of the Earth's continents (Yu 2007), where evaporation is enhanced. This is particularly true during wintertime, from December to February in the Northern Hemisphere (NH) and from June to August in the Southern Hemisphere (SH). Moreover, the wintertime evaporation is subject to polar-ward transport, thus it contributes to the global warming of the polar regions and is especially pronounced in the Arctic, where the northward transport of oceanic currents is most extended.

When describing the efficiency of water evaporation at the global scale, the contribution of the Earth's rotary motion must be mentioned, as the lower weight of all objects at the Equator (c. $0.5 \%$ ) compared to the Poles (Persson 1998). Therefore, evaporating molecules are "pulled- outwards" from the rotating planet, particularly within the tropics. This enhances the rate of evaporation in the tropics, especially within the Intertropical Convergence Zone, located in the NH. Thus, the rotating Earth also imparts airborne eddies that are enhanced within the Hadley and Mid-latitude cells in the NH (Garbalewski, Marks 1987).

As c. $505,000 \mathrm{~km}^{3}$ of water vaporizes annually from the Earth (Woś 2000), with the dominating share of evaporation (accounted for $86 \%$ ) originating from the ocean, (e.g. Deese 2008), the contribution of water vapor to airborne rotary over the oceans enforces the overall circulatory motion that forms gyrating convective cells within the main tropospheric lows. Thus, water vapor induced upward motion is here presented as an important factor that contributes to convections, impacting on pressure gradients and related wind fields, as well as humidity and precipitation fields over water compartments, and less so over snow/ice and land/vegetation surfaces.

Considering that water vapor is the main renewable and vertically movable compound of air, the upward flux of moisture controls the vertical distribution of energy, which is mainly rotational, and is subtracted from the evap- 
orating surfaces. This enforces the overall eddy motion of air, which is particularly enhanced under a high relative humidity and is increases with elevation. The enhanced rotary motion was also found under gusty events (Marks 1985), who correlated the rates of wind speed increments with related phase changes in wind direction.

Under an up-draft, the ambient air temperature decreases, and water vapor tends to condense on aerosols, ice crystals and droplets, particularly if these contain ions (Marks 2014). The condensed water ceases the rotary motion and forms droplets that precipitate. At that stage, the upward directed motion is replaced by the downward motion of air that begins to rotate in the opposite direction.

In the liquid phase, the displacement of a single water molecule may be based on both rotational and oscillatory motions that result in spiraling advancement performed among other molecules in fresh water, or among spherical ionic hydrates in saline waters. During such motions, a set of interactions and related dissipation of rotational-oscillatory energy, as well as the gaining of rotational energy from thermal or solar radiation, may simultaneously take place.

A single airborne water molecule may be described as a dipole object with dominating mass positioned in an oxygen nucleus (Miessler, Tarr 2003), and a much lighter hydrogen arm that may develop strong and an upwardly directed rotary movement. Such a unique configuration of a water molecule with a distinct bi-hydrogen rotor-arm is presented in Figure 1.

Assuming that the rotary motion of the $\mathrm{H}-\mathrm{O}-\mathrm{H}$ molecule is induced by a bi-hydrogen-rotor containing only $11 \%$ of the molecule mass, the bi-hydrogen arm is presented as the most distinct rotational feature that is unique among other airborne molecules. The perfect rotational configuration of the water molecule is likely induced by the $\mathrm{H}-\mathrm{H}$ rotor, which may immediately initiate and then sustain the rotational motion around the oxygen atom that bears $89 \%$ of mass. Considering that the overwhelming mass in the molecule is located in extremely small, centrally positioned nuclei of $(\mathrm{D} / \mathrm{d}=105)$, gathering approximately 99.9\% of mass (Sobkowski 1981), such an object with an angle of $104.45^{\circ}$ between three centers of mass (Finney 2001) may immediately tend to initiate rotary motion, particularly when a molecule is forced into displacement or acceleration.

\section{Experimental methods}

This section presents the methodological approach used to detect the rotational features of evaporating water molecules. The features were firstly sensed in laboratory conditions by means of airborne rotary detection discs suspended over evaporating water surfaces and are presented in Section 2.1. Next, the experimental method used to trace airborne turbulence effects during field observations is presented in Section 2.2.

\subsection{Laboratory experiments}

The first set of experiments was conducted using airborne rotary detection discs (ARDD), made of an absorbent cotton wool of $60 \mathrm{~mm}$ diameter, 2-3 mm thickness and a weight of 0.2-0.26 g. Discs were suspended c. 2-6 cm above a clean tap water surface, allowing continuous absorption of just the evaporating water molecules and the inception of upwardly directed rotational features. Discs were suspended over water by a 2-3 $\mathrm{m}$ long polyamide thread and placed in the center of a water vessel covered by a hood with an open slot. Such a setup allowed for the observing of the rotational features steadily integrated to discs that absorbed the upwardly directed water vapor and started to rotate.

A second set of experiments was conducted using ultralight polyurethane foam discs of $36 \mathrm{~mm}$ diameter, $1 \mathrm{~mm}$ thickness and a 0.05-0.07 g weight. Discs were suspended

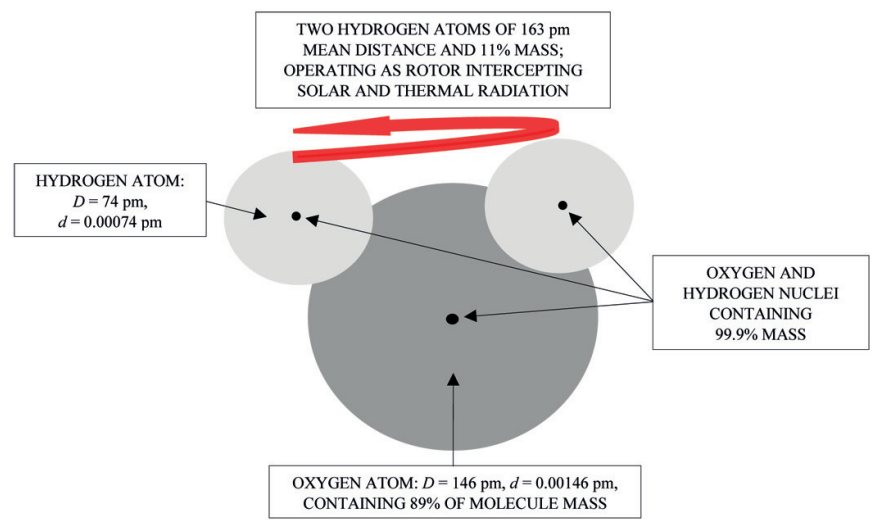

Fig. 1. A perfect rotational configuration of a water molecule posing a light bi-hydrogen rotor-arm revolving around a centrally positioned and heavy oxygen nucleus, along with marked diameters of the oxygen and hydrogen atoms (D) and their nuclei (d) (Finney 2001; Silberberg 2006) 
on c. $10 \mathrm{~cm}$ long polyamide thread attached to a light Styrofoam float of 3-4 mm diameter, placed in the center of a petri dish with a centrally positioned slot. After filling the petri dish with a small volume of distilled water, the float and the thread were free to rotate, since the disc and the float were suspended by means of water surface tension (Fig. 2).

The ultralight discs were more sensitive to the detection of upwardly directed rotary motion of water vapor due to an approximately 4 times lower weight compared to cotton discs. During the experiments, the disc rotary was observed or recorded by a camera. Special attention was given to limit the turbulent motion in the room prior to each observation, thus experiments started after the airborne rotary indicated by the exposed disc ceased. The most visible effects were observed under a relatively low air humidity $(R H)$ of $30-60 \%$ and water temperatures c. $5-20^{\circ} \mathrm{C}$ higher than the air temperature in the laboratory room. Typically, tap water evaporated from a clean glass or plastic container placed below the suspended disc. In the preceding phase of the experiments, both water/ air and disc motions ceased. During the experiments, air temperature $(\mathrm{Ta})$ and air relative humidity $(\mathrm{RH})$ were measured using thermocouples, while water surface temperature $(T w)$ and temperature radiated by the discs $(T d)$ were measured with a pyrometer. Typically, all thermal parameters were traced before and just after exposition. The majority of observations were conducted within the latitudes of $53^{\circ} 40^{\prime} \mathrm{N}-54^{\circ} 30^{\prime} \mathrm{N}$, while one experiment was conducted in the $\mathrm{SH}$ on the plane flying from Bali (Indonesia) to Kuala Lumpur (Malaysia) within the latitudes of $5^{\circ} \mathrm{S}$ to $6^{\circ} \mathrm{S}$.

To detect the direction of the water molecules rotary motion in the SH, a simplified setup was used. During this experiment, a cotton disc was positioned at the center of a c. $30 \mathrm{~cm}^{3}$ glass vessel over semi-still water covered by a hood under an air temperature of c. $20-22^{\circ} \mathrm{C}$.

\subsection{Field experiments}

Field observations were completed in several locations, with the majority situated within the coastal zone of the Pomeranian Bay (southern Baltic Sea) from 2015 to 2018. In order to trace the direction of the rotary motion that composed the airborne eddies, a set of ribbons exposed in a vertical profile, visualizing the "undulation" of air currents, was used. Ribbons with a width of $1 \mathrm{~cm}$ and a length of c. $2.5 \mathrm{~m}$ were kept in the air on a $20 \mathrm{~cm}$ long polyamide thread fastened to a mast or pole and exposed in a vertical profile at 2, 4, and $6 \mathrm{~m}$ (Fig. 3A) or at 2, 2.5 and $3 \mathrm{~m}$ above the ground (Fig. 3B). The ribbons allowed for the obser- vation of the dominating direction of the rotary motion composing the airborne eddies and related sequence changes in wind direction, as well as for the counting of the number of turns performed by each ribbon during the exposition.

In addition, air temperature, air humidity and atmospheric pressure were recorded by a routine meteorology station operated by the Marine Station of the University of Szczecin, located in Międzyzdroje at the Pomeranian Bay (southern Baltic Sea coast). Special attention was given to observing the rotational behavior of the ribbons under gusty winds.

Over 60 observations were completed from 2015 to 2018. However, the obtained results are rather qualitative since they were collected in two locations on the beach using a mast with a height of $6.5 \mathrm{~m}$ (Fig. 3A), or on the top of a dune using a wooden pole reaching only 3.5 m elevation (Fig. 3B). In addition, each experiment was conducted under different atmospheric settings that configured turbulent motion in air, reflecting changes in spatial and temporal baric conditions, as well as fluctuations in air relative humidity.

\section{Results}

This section presents both the results obtained during laboratory investigations conducted under different thermal conditions (Section 3.1), and those obtained during field observations performed in the coastal zone within the southern Baltic Sea (Section 3.2).

\subsection{Laboratory experiments}

The first set of experiments was conducted using cotton discs under conditions of similar water and air temperature $\left(T w / T a / T d\right.$ of $\left.19.0 / 19.6 / 19.6^{\circ} \mathrm{C}\right)$ and a $R H$ of $40 \%$. The observations revealed that a disc placed above evaporating water collected vapor and slowly developed a rotational motion depicted by a $1 / 4 ; 2 / 4 ; 3 / 4$ and full disc turn, completed in 5, 9, 12 and 28 minutes of exposition, respectively. The motion of the disc indicated a very slow, but visibly counter-clockwise (CCW) direction of the rotary motion that was observed from above the disc.

After exposition, the set of thermal parameters $\mathrm{Tw} / \mathrm{Ta} / \mathrm{Td}$ was $18.5 / 19.6 / 17.5^{\circ} \mathrm{C}$, indicating that the temperature of the water surface decreased by c. $0.5^{\circ} \mathrm{C}$, while the temperature of the exposed disc decreased by $2.1^{\circ} \mathrm{C}$, indicating that the disc absorbed a significant portion of water vapor, which in turn started to evaporate from the disc. The obtained results confirmed that the water molecules under transition from a liquid to a gaseous phase develop a dominating $\mathrm{CCW}$ rotary motion in the $\mathrm{NH}$. 


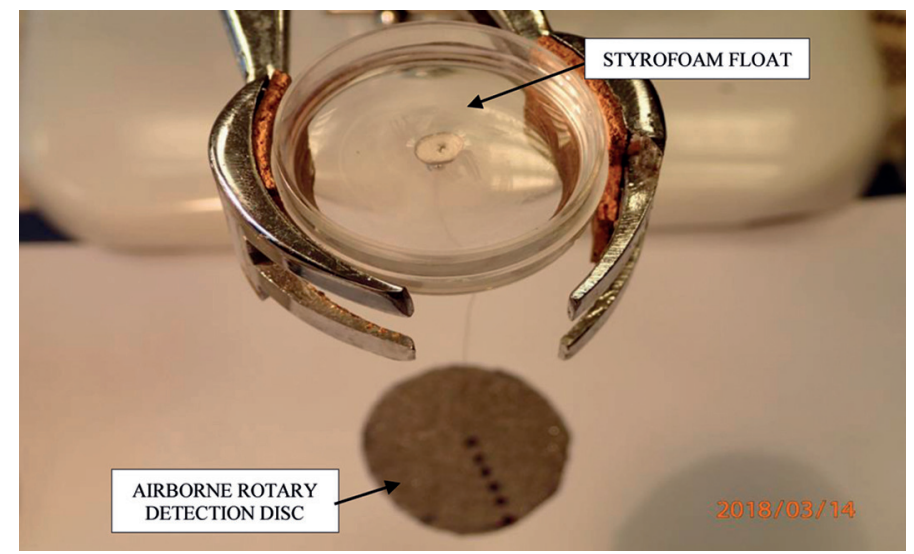

Fig. 2. Experimental setup used to sense the rotational features of water vapor with the exposition of an ultralight airborne rotary detection disc, kept in place by a Styrofoam float placed in a petri dish with central slot

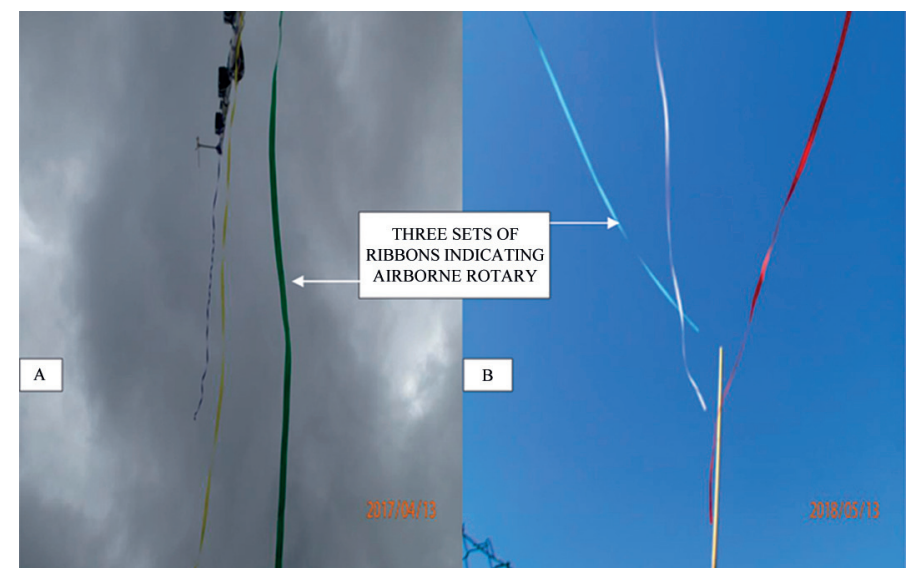

Fig. 3. Sets of ribbons indicating spiraling motion in air under atmospheric low (A) and high (B) pressure patterns at 2, 4, $6 \mathrm{~m}$ (A) and at 2, 2.5, $3 \mathrm{~m}$ above the ground (B)

An additional experiment was conducted at the initial conditions of water temperature $T w=30^{\circ} \mathrm{C}$, and $(T a)=(T d)$ at $19.8^{\circ} \mathrm{C}$. During the observation, the disc developed a faster rotational motion compared to the experiment under $T w \approx T a$ of $\left(19.0-19.6^{\circ} \mathrm{C}\right)$, and performed 1, 2, 3 and 4 full turns in a CCW direction in 5, 10, 14 and 19 minutes, respectively. After 20 minutes of exposition, the set of $(T w) /(T a) /(T d)$ parameters were observed as $28.0 / 19.9 / 19.0^{\circ} \mathrm{C}$, and the surface temperatures of ARDD decreased by $0.8^{\circ} \mathrm{C}$, indicating that the cotton material was saturated by water vapor, which started to re-evaporate.

Next, a set of experiments with $(T w-T a)>20^{\circ} \mathrm{C}$ were conducted after previously boiling and then cooling water to $60-40^{\circ} \mathrm{C}$. During experiments, a vessel with steaming water was placed below a disc, which started to rotate almost instantly. This observation indicated that the disc developed a more vigorous rotational motion, although after 2-3 CCW turns, completed during 2-3 minutes, the rotary movement typically attenuated. This showed that the rotary movement of the disc introduced in the first phase (when the water vapor was collected into the disc pores) was subsequently reduced due to condensation and re-evaporation. Thus, the results also indicated that the process of condensation may be based on a sudden reduction of rotary motion.

Observations in the $\mathrm{SH}$ indicated that evaporating water molecules develop a clockwise (CW) directed rotary motion, the opposite direction to that detected in the $\mathrm{NH}$.

Experiments with ultralight polyurethane discs confirmed the above reported direction of water vapor induced rotational features; however, the rotary motion was significantly faster. For example, a disc exposed $6 \mathrm{~cm}$ over the water at a room temperature of $25^{\circ} \mathrm{C}$ performed 1-2 turns during the first 20 seconds of exposition, and the number of turns recorded in the first phase of the experiments typically increased with the temperature of water.

\subsection{Field experiments}

Three ribbons exposed in a vertical profile allowed for the observation of the direction of rotary motion and for the qualification of a scale of eddies. In general, the read- 
ings conducted under low pressure conditions indicated that CCW spiraling eddies dominate (see Fig. 3A). Typically, the number of circuits performed by the ribbons during 1-minute intervals at a $3 \mathrm{~m}$ elevation exceeded 10 under atmospheric lows of high wind speed conditions and dropped to 0-2 under the atmospheric highs of low wind speed. In general, the recorded number of turns also tended to increase with elevation, as indicated by the blue ribbon exposed at $6 \mathrm{~m}$ above ground (see Fig. 3A). In addition, during gusty events, the frequency of rotaries significantly increased. In general, with increasing wind speed and a rise in air humidity, the number of airborne eddies increased. However, the airborne rotational activity was also found to depend on a static stability (difference in temperature between water and air) that typically overshadowed the impact of air humidity under $T w<T a$.

In contrast, under high pressure conditions, the dominance of clockwise directed airborne eddies was observed in Międzyzdroje (southern Baltic Sea coast). In addition, the comparison of ribbon turns observed under moderate wind speed conditions indicated roughly 3-5 times more CCW turns of ribbons during 5-minute intervals conducted under the low-pressure conditions with an air humidity of $95-98 \%$ compared to $\mathrm{CW}$ turns performed under high pressure systems with an air humidity of 50-55\%. However, under the transition from low to high baric conditions, both directed rotaries were observed, with a dominance of $\mathrm{CCW}$ eddies at lower elevations.

\section{Discussion}

In this section, the rotational principles that configure the process of water evaporation, and the concept of bi-hydrogen bounds that allow the grouping of the water molecules, are presented (Section 4.1). The related airborne interactions that impact the turbulent eddies in the troposphere are elucidated in Section 4.2. The subsequent process of water vapor condensation is presented as a result of rotational energy dissipation in Section 4.3. In addition, the rotational configuration of greenhouse gases is presented in Section 4.4.

\subsection{Rotational principles of evaporation}

Considering that water molecules transit an upwardly directed rotary movement, it is inferred that the process of water evaporation operates on rotational principles that are assembled in a warmer sub-surface microlayer that is placed just below the air-water interface layer (Fig. 4).

Furthermore, considering that evaporating water transits a very high and precise rate of energy, it is assumed that the process of evaporation may be based on the rotational momentum. Thus, the combined partial momentums collected by the polymeric chain of $\left({ }^{\mathrm{H}-} \mathrm{O}^{-\mathrm{H}}\right)_{\mathrm{n}}$ allow the transition of water molecules via a typically colder surface tension layer and evaporate i.e. one molecule become airborne (Fig. 4).

Considering that water molecules in the subsurface and in the immediate surface tension layer may have a fairly random character (Holman, Stone 2001), and that the surface tension layer is typically colder than the layer below, it is inferred that the process of lining-up and spiraling water molecules originates in the warmer subsurface layer (Fig. 4). In this way, the rate of rotational energy gathered by the grouped $\left({ }^{\mathrm{H}-} \mathrm{O}^{-\mathrm{H}}\right)_{\mathrm{n}}$ polymers may randomly exceed the energy of the hydrogen bounds (Silberberg 2006). Thus, the evaporating molecules undergo wrenching with a substantial (rotational) share of energy. This energy is subtracted from the immediate water surface microlayer. Therefore, the rotational hydrogen bounds termed here may operate based on hydrogens-to-oxygen-to-hydrogens rotational bounds or rotational fastening, i.e. the arms of interacting molecules may be positioned perpendicularly to each other (Fig. 5).

In this way, the grouping of water molecules may be based on the rotational interactions among bi-hydrogen rotors, inducing bi-hydrogen bounds combining the energy of contributing molecules. This allows for the top water molecule to evaporate with the share of rotational energy that is taken over. However, the anticipated rotational principles of bi-hydrogen bounds and related interactions among water molecules need to be confirmed with future experiments.

Furthermore, it is inferred that all processes of evaporation that transit a substantial rate of latent heat may operate on the same rotational principles that allow the liquid to gaseous phase change for water molecules.

\subsection{Water vapor induced rotational interactions}

The molecular weight of $\mathrm{H}_{2} \mathrm{O}$ is $18 \mathrm{u}$, and a single water molecule is 1.55 lighter compared to $28 \mathrm{u}$ for $\mathrm{N}_{2}$ and 1.77 lighter compared to $32 \mathrm{u}$ for $\mathrm{O}_{2}$. Thus, water vapor may play an enforcing role in airborne motion (Holman, Stone 2001). For example, the oscillatory motion of water molecules in the air, as estimated by the root mean square speed (rmss) according to equation (1) (Lerner, Trigg 1991), ranges from $2,215 \mathrm{~km} / \mathrm{h}$ to $2,322 \mathrm{~km} / \mathrm{h}$ at air temperatures of $0^{\circ} \mathrm{C}$ and $27^{\circ} \mathrm{C}$, respectively (Table 1 ). The values of rmss were calculated as follows:

$$
r m s s=(3 k T / M)^{1 / 2}
$$


Table 1. Estimated values of oscillatory motion ( $r m s s$ ) under temperature of $0^{\circ} \mathrm{C}$ and $27^{\circ} \mathrm{C}$ for some gases in troposphere

\begin{tabular}{|l|c|c|c|}
\hline \multirow{2}{*}{ Gas } & \multirow{2}{*}{$\begin{array}{c}\text { Atomic Mass } \\
M \text { in u }\end{array}$} & \multicolumn{2}{|c|}{$\begin{array}{c}r m s s ~ i n ~ k m / h \\
\text { under temperature of }\end{array}$} \\
\cline { 3 - 4 } & & $0^{\circ} \mathrm{C}$ & $27^{\circ} \mathrm{C}$ \\
\hline $\mathrm{N}_{2}$ & 28 & 1,776 & 1,861 \\
\hline $\mathrm{O}_{2}$ & 32 & 1,661 & 1,741 \\
\hline $\mathrm{H}_{2} \mathrm{O}$ & 18 & 2,215 & 2,322 \\
\hline $\mathrm{CO}_{2}$ & 44 & 1,409 & 1,485 \\
\hline $\mathrm{CH}_{4}$ & 16 & 2,349 & 2,462 \\
\hline
\end{tabular}

where: $k=1.38064852(79) \times 10^{-23}$ is a Boltzmann constant $(\mathrm{J} / \mathrm{K}), T$ is absolute temperature $(\mathrm{K})$, and $M$ is the atomic mass of gaseous molecule $(\mathrm{u})$.

The calculated values of rmss due to $\mathrm{H}_{2} \mathrm{O}$ are significantly higher compared with that estimated for $\mathrm{N}_{2}$ and $\mathrm{O}_{2}\left(1,776 \mathrm{~km} / \mathrm{h}, 1,861 \mathrm{~km} / \mathrm{h}\right.$ for $\mathrm{N}_{2}$ and $1,660 \mathrm{~km} / \mathrm{h}$, $1,741 \mathrm{~km} / \mathrm{h}$ for $\mathrm{O}_{2}$, at air temperatures of $0^{\circ} \mathrm{C}$ and $27^{\circ} \mathrm{C}$, respectively). The comparison of these values indicates that water molecules that are both lighter and c. $500 \mathrm{~km} / \mathrm{h}$ faster may enforce the motion of other airborne molecules, i.e. $\mathrm{N}_{2}$ and $\mathrm{O}_{2}$, which are slower. This indicates that the motion of air is driven by faster spiraling and oscillating molecules of water vapor.
In addition, the airborne water intercepts thermal radiation that is directed upward from typically warmer water or land surfaces (Fig. 6). Thus, the net motion of air is further enhanced by water molecules, which interacts with nitrogen and oxygen diatomic molecules that are more abundant in the air. For example, the maximum concentration of water vapor molecules in the air above the water surface under an air temperature of $10^{\circ} \mathrm{C}$ indicates that a single water vapor molecule interacts with 67 dinitrogen and 16 dioxygen molecules. However, at a temperature of $30^{\circ} \mathrm{C}$, a single $\mathrm{H}_{2} \mathrm{O}$ interacts with $9 \mathrm{~N}_{2}$ and $5 \mathrm{O}_{2}$ molecules. Thus, by increasing the air temperature, the air parcels develop a more enhanced rotary motion that is further energized by the continuous flux of rotating $\mathrm{H}_{2} \mathrm{O}$ molecules and the related inception of thermal radiation.

Considering that the flux of water vapor is the main factor enforcing the upward motion in the air, its integrated flux generates baric gradients and a related compensative transport of air towards the centers of atmospheric lows. However, since gaseous molecules are in free motion, the airborne transport of air parcels is modified by the Coriolis force (Persson 1998), as well as continental/land barriers and surface roughness, along with

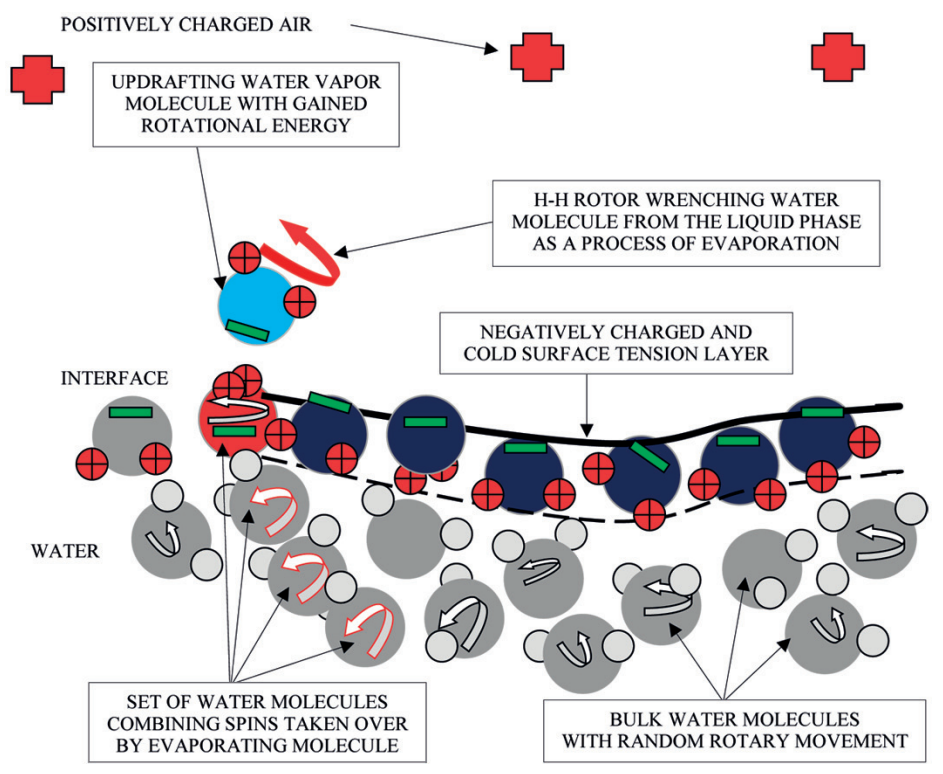

Fig. 4. Simplified cross-section of the air-water interface introducing the process of evaporation as a result of the rotational grouping of water molecules in the liquid phase, allowing for the transition of a top molecule via the surface tension layer with a precise portion of rotational energy (latent heat)

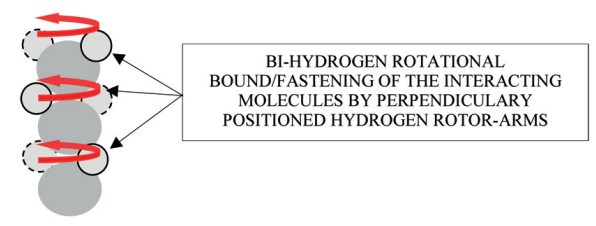

Fig. 5. General scheme of perpendicular bi-hydrogen-to-oxygen-to-bi-hydrogen $\left({ }^{\mathrm{H}-} \mathrm{O}^{-\mathrm{H}}\right)_{3}$ rotational bound, allowing the grouping of successive water molecules that combine their partial rotational spins in the liquid phase 


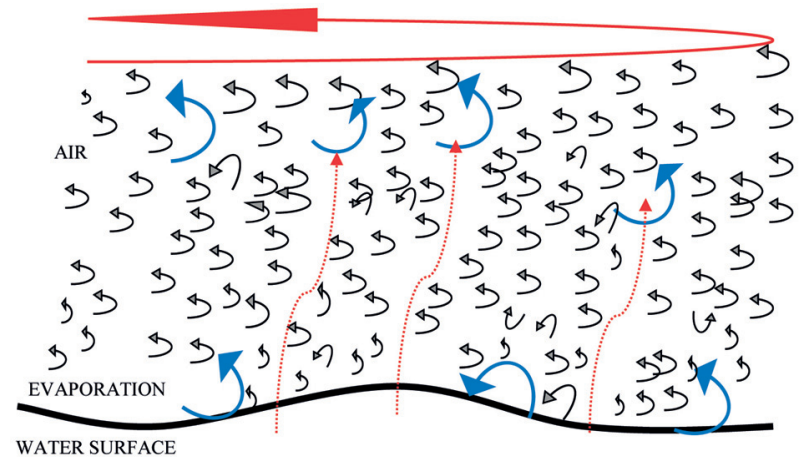

Fig. 6. Illustration of the counter-clockwise, convective rotational-translational motion of water vapor in the NH (marked by blue arrows), enforcing motions of $\mathrm{N}_{2}$ and $\mathrm{O}_{2}$ (marked by small black arrows) that may result in a whirling parcel of air (marked by large red arrow). In addition, a contribution of thermal radiation intercepted by water vapor is indicated by broken red arrows

thermal stability of air/water, air/land, air/snow/ice or air/ vegetation interfaces. The superimposition of these factors shapes a spatial and temporal motion of air parcels from molecular-microscopic to macroscopic scales within the whole column of troposphere, as shown in Figure 6.

Both, the upward motion and the "memorized" Coriolis momentum of the Earth rotary movement (at a given place of evaporation) forces the water vapor molecules, as well as all air parcels, to whirl in the $\mathrm{CCW}$ or $\mathrm{CW}$ direction in the respective $\mathrm{NH}$ or $\mathrm{SH}$, as depicted in Figure 6. This enforcement is continued until the water molecules condense and release the rotational share of latent heat. From this stage onwards, the previously uplifted air molecules descent and slowly develop a clockwise rotary motion in the $\mathrm{NH}$, and counterclockwise in the $\mathrm{SH}$.

The rmss values listed in Table 1 may be used to calculate the rate of energy due to oscillatory motion $E_{o}$, which can be estimated using equation (2):

$$
E_{o}=M(r m s s)^{2} / 2
$$

A comparison of $E_{o}$ with "latent heat of water vaporization (lhwv) that range from $2,250 \mathrm{~J} / \mathrm{g}$ to $2,259 \mathrm{~J} / \mathrm{g}$ under the water temperature of $0^{\circ} \mathrm{C}$ and $100^{\circ} \mathrm{C}$ respectively, indicates the overwhelming domination of the rotational share of energy due to lhwv that significantly exceeds the energy due to oscillatory $E_{o}$, under all ranges of tropospheric temperatures.

\subsection{Water vapor impact on airborne eddies}

The outlined research allows to perceiving airborne turbulence as induced by rotating and up-drafting water vapor molecules. Thus, steadily renewed fluxes of water vapor generate the upward motion of air that originates at the molecular scale and is proceeded up to a thousand $\mathrm{km}$ eddies, forming cyclones and hurricanes. In addition, water vapor intercepts heat that is radiated by typically warmer surfaces. However, at all stages of airborne turbulence development, a share of rotational energy is simultaneously dissipated among other molecules, until the condensation of water occurs. This ceases the upward motion in the troposphere, and from this stage onwards, the energy dissipation goes downward, is proceeded from large to smaller eddies, and finally to the molecular interactions and heat (Kraus 1972).

The above presented research may be of significance for the more precise modeling of water vapor related tropospheric processes, which are rotational (non-linear) in nature. Note that water vapor fluxes also depend on humidity gradients at the water/air interface, i.e. the lower values of humidity enhance the evaporation. On the other hand, the rate of evaporation also increases with rising water temperatures and wind speed e.g. (DeCosmo et al. 1996; Smith et al. 1996). In this way, air continuously exchanges and equilibrates water vapor partial pressures and relative humidity acts as an interactive factor controlling both upward and downward directed water vapor fluxes (Kraus 1972; Yu 2007; Kolendowicz et al. 2016; Szwejkowski et al. 2017).

\subsection{Rotational configuration of greenhouse gasses}

All greenhouse gases also pose a distinct rotational shape. For example, $\mathrm{CO}_{2}, \mathrm{CH}_{4}$ and trace gases such as: $\mathrm{O}_{3}$, $\mathrm{NO}_{2}, \mathrm{~N}_{2} \mathrm{O}$, and $\mathrm{SO}_{2}$. Thus, they may effectively absorb heat (IPCC 2014). Among them, $\mathrm{CH}_{4}$ (the second important greenhouse gas, considering its present impact on warming the troposphere) is particularly regarded as the most efficiently absorbing constituent. Since $\mathrm{CH}_{4}$ poses active rotors composed of four hydrogens, the molecule absorbs heat even more efficiently than water. In addition, the limited methane weight of $16 \mathrm{u}$ offers enhanced vertical penetrability in the troposphere (Table 1).

Moreover, the comparison of water vapor atomic mass and rmss with other tropospheric gases (Table 1) indicates 
that among greenhouse gasses, significantly heavier $\mathrm{CO}_{2}$ may tend to compose the lower troposphere, while substantially lighter $\mathrm{CH}_{4}$ and $\mathrm{H}_{2} \mathrm{O}$ may be responsible for the updraft and radiative forcing in the whole troposphere. On the other hand, warmer troposphere enhances evaporation of water that further contributes to the interception of heat, and enhances the net effect of radiative warming. Therefore, $\mathrm{CO}_{2}$ and $\mathrm{CH}_{4}$ mainly mediated the trapping of heat and should be regarded as the primary cause of warming, as pointed by Storch and Bray (2017). On the other hand, enhanced evaporation of water has a more indirect, but dominating contribution. In general, the rotational absorption of heat by gaseous compounds in the troposphere contributes to the overall energy budget of the Earth.

In general, the rotational features induced by water vapor and greenhouse gases call for more expanded and interdisciplinary research. In particular, the unique rotational configuration of hydrogen rotors seems to be responsible for the gain and distribution of rotational "latent" heat by water vapor and greenhouse molecules in the whole column of troposphere. However, the most profound question refers to the rotational nature of solar and thermal radiation, and the overall importance of rotary motion in biological molecules as well as in the whole Universe.

\section{Conclusions}

Laboratory and field experiments allowed for the following conclusions:

- The process of water evaporation may be based on the unique ability to combine partial spins of a few water molecules after gaining a sufficient energy that allow the top molecule to transit via the surface tension microlayer.

- The evaporating water molecules develop counterclockwise rotational kinetics in the Northern Hemisphere, while the clockwise rotary motion in the Southern Hemisphere needs to be confirmed.

- At the moment of evaporation, the water molecules gain a very high share of rotational energy, denoted as "latent heat of evaporation", which is transited by the rotating bi-hydrogen arm into the air.

- The rate of "latent heat" carried with water vapor may be shared with other molecules in air and is simultaneously renewed by the interception of thermal radiation.

- During the process of condensation, the rotational energy due to water molecules is released in the form of radiation that corresponds to the "latent heat of condensation".
- An increase in air humidity enhances the number of spiraling eddies configuring airflows.

- Further interdisciplinary experiments tracing the unique ability of water molecules to assembly, sustain and transit rotary, especially in biological molecules, are needed.

- The outlined results may be used to enhance the production of electricity from wind farms especially that operating over the high water evaporative areas as maritime and coastal locations.

\section{Acknowledgement}

Ms. Anna Marczak is acknowledged for conducting experiment over the Southern Hemisphere.

\section{Bibliography}

DeCosmo J., Katsaros K.B, Smith S.D, Anderson R.J., Oost W.A., Bumke K., Chadwick H., 1996, Air-sea exchange of water vapor and sensible heat: The Humidity Exchange Over the Sea (HEXOS) results, Journal of Geophysical Research, 101 (C5), 12001-12016, DOI: 10.1029/95JC03796

Deese W.C., 2008, UXL Encyclopedia of Science, available at https://www.encyclopedia.com

Finney J.L., 2001, The water molecule and its interactions: the interaction between theory, modelling, and experiment, Journal of Molecular Liquids, 90 (1-3), 303-312, DOI: 10.1016/S0167-7322(01)00134-9

Garbalewski C., Marks R., 1987, Latitudinal characteristics of aerosol distribution in the near surface air over the Atlantic. Acta Geophysica Polonica, 35 (1), 77-86

Holman J., Stone P., 2001, Chemistry, Nelson Thornes, 314 pp. IPCC, 2014, Climate change 2014: Synthesis Report, Contribution of Working Groups I, II and III to the Fifth Assessment Report of the Intergovernmental Panel on Climate Change, The Core Writing Team, R.K. Pachauri, L.A. Meyer (eds.), IPCC, Geneva, Switzerland, 151 pp.

Kolendowicz L., Taszarek M., Czernecki B., 2016, Convective and non-convective wind gusts in Poland, 2001-2015, Meteorology Hydrology and Water Management, 4 (2), 15-21, DOI: $10.26491 / \mathrm{mhwm} / 63636$

Kraus E.B., 1972, Atmosphere-ocean interaction, Oxford University Press (Clarendon), 275 pp.

Lerner R.G., Trigg G.L., 1991, Encyclopedia of Physics, $2^{\text {nd }}$ edition, VHC publishers, $1408 \mathrm{pp}$.

Marks R., 1985, Attempt of regarding the effect of wind gustiness of the sea dynamic roughness as a factor of mass exchange through air-sea interface, Polish Polar Research, $6(4), 459-474$ 
Marks R., 2014, Bubble rotational features - preliminary investigations, Journal of Oceanography and Marine Research, 2 (4), DOI: 10.4172/2332-2632.1000128

Miessler G.L., Tarr D.A., 2003, Inorganic chemistry, $3^{\text {rd }}$ edition, Prentice Hall, 720 pp.

Persson A., 1998, How do we understand the Coriolis Force, Bulletin of the American Meteorological Society 79 (7), 1373-1385, DOI: 10.1175/1520-0477(1998)079<1373:HDW UTC $>2.0 . C O ; 2$

Pidwirny M., 2011, Evaporation, [in:] Encyclopedia of Earth, J. Cutler (ed.), available at http://editors.eol.org/eoearth/wiki/ Evaporation (data access 05.03.2019)

Silberberg M.S., 2006, Chemistry. The molecular nature of matter and change, $4^{\text {th }}$ edition, McGraw-Hill, 1088 pp.

Smith S.D., Katsaros K.B., Oost W.A., Mestayer P.G., 1996, The impact of the Hexos programme, Boundary-Layer Meteorology, 78 (1-2), 121-141, DOI: 10.1007/BF00122489
Sobkowski J., 1981, Chemia jądrowa, PWN, Warszawa, 251 pp. Storch H., Bray D., 2017, Models manifestation and attribution of climate change, Meteorology Hydrology and Water Management, 5 (1), 47-52, DOI: 10.26491/mhwm/67388

Szwejkowski Z., Dragańska E., Cymes I., Timofte C.M., Suchecki S., Craciun I., 2017, Rainfall and water conditions in the region of the upper glacial in Europe, Meteorology Hydrology and Water Management, 5 (1), 15-28, DOI: $10.26491 / \mathrm{mhwm} / 65538$

Woś A., 2000, Meteorologia dla geografów, Wydawnictwo Naukowe PWN, Warszawa, 313 pp.

$\mathrm{Yu}$ L., 2007, Global variations in oceanic evaporation (1958-2005): The role of the changing wind speed, Journal of Climate, 20 (21), 5376-5390, DOI: $10.1175 / 2007$ JCLI1714.1 